\title{
HYVÄN ELÄMÄN EPÄVARMAT TEKNOLOGIAT MEDIAYHTEISKUNNASSA ANALYYSI TUNNUSTAMISESTA, HÄPEÄSTÄ JA VIHASTA
}

Mitä tarkoittaa hyvä elämä mediayhteiskunnassa? Hyvää elämää voi tarkastella universaalina filosofisena periaatteena, mutta myös historiallisesti ja sosiaalisesti muuttuvana käytäntönä. Median tutkijana minua kiinnostaa jälkimmäinen mahdollisuus eli erityisesti se, millaiset mediavälitteiset teknologiat tuottavat hyvää elämää mediayhteiskunnassa ja mitä seurauksia niillä on mediakyllästeisessä sosiaalisessa todellisuudessamme. Pohdin, miten media esittää, tuottaa ja ylläpitää käsityksiä hyvästä elämästä ja millaisia kulttuurisia ja sosiaalisia seurauksia näillä käsityksillä on mediayhteiskunnan kannalta. Ajattelen, että se mitä pidämme mediayhteiskunnassa moraalisesti ja eettisesti arvokkaana, on historiallisesti muuttuvaa ja sitä on myös tarkasteltava kriittisesti tässä jatkumossa (vrt. Innis 1951).

Olen jakanut artikkelin kolmeen osaan. Ensimmäisessä osassa luonnehdin elämää mediayhteiskunnassa ja pohdin, mitä medialisaatio (engl. mediatization) tarkoittaa hyvän elämän näkökulmasta ja miten medialisoitunut hyvä elämä näkyy nykyisessä mediaelämässämme (ks. Deuze 2013). Toisessa osassa tarkennan katseeni hyvän elämän medialisaatioon kuuluvaan julkisen elämän intimisoitumiseen (ks. esim. Illouz 2007). Tarkastelen mediajulkisuuden intimisoitumista etenkin tunnustamisen näkökulmasta. Pyrin osoittamaan, miten tunnustaminen muodostaa mediayhteiskunnan yhden keskeisen hyvän elämän teknologian, yhteisöllisesti hyväksytyn tavan tuottaa ja neuvotella hyvää ja hyveellistä elämää. Artikkelin kolmannessa ja viimeisessä osassa tutkin medialisoituun tunnustamiseen liittyviä emotionaalisia järjestyksiä. Emotionaalisilla järjestyksillä tarkoitan tunteiden kulttuurisia ja sosiaalisia struktuureja, tässä erityisesti tunnustamiseen olennaisesti kietoutuvia vapautuksen, mutta myös ulossulkemisen pelon ja siihen liittyvän häpeän ja myös vihan tunteita. Tulkitsen, että tunnustaminen toimii mediayhteiskunnassa hyvän elämän teknologiana, koska se tarjoaa mahdollisuuden julkiseen neuvotteluun hyvän elämän rajoista. Samalla se toimii teknologiana, joka tuottaa epävarmuutta ja uhkaa sulkea ulos - näin tunnustaminen hyvän elämän tuottamisen tapana synnyttää mediayhteiskunnassa myös häpeää ja sen nostattamaa vihaa.

HYVÄ, MEDIALISOITU ELÄMÄ

Elämme mediayhteiskunnassa, jota luonnehtii medialisaatio. Medialisaatio tarkoittaa yksinkertaisesti ilmaistuna sitä, että käsityksemme siitä, millainen yhteiskunta on, miten ihmisten väliset suhteet toimivat siinä ja miten me yksilöinä ja subjekteina liitymme tuohon yhteiskuntaan ja sen sosiaalisten suhteiden verkostoihin on muuttunut yhä mediavälitteisemmäksi ja mediakyllästeisemäksi (ks. esim. Couldry \& Hepp 2017; Lundby 2014; Hjarvard 2013).

Medialisaatio näkyy siinä, että julkinen urbaani tila on täynnä hyvää elämää puhuttelevia mediavälitteisiä viestejä, mainoksia, lööppejä, hyveellisesti tai paheellisesti käyt- 
täytyviä matkapuhelimiinsa puhuvia ihmisiä, kamerakännyköillään kuvaavia henkilöitä tai kahvilassa verkossa "surfaavia" kansalaisia. Myös oma henkilökohtainen elämämme strukturoituu nykyään tyypillisesti erilaisten mediavälitteisten hetkien ja tuokioiden kautta. Yhä useammin kommunikaatiomme maailman ja toisten ihmisten kanssa tapahtuu median välittämänä: puhelimessa, sähköpostissa, Facebookissa, twitterissä tai skypessä. Voi ajatella, että olemme yhteydessä paitsi toisiin, myös itseemme ja omiin moraalikäsityksiimme median välityksellä. Rakennamme hyvää elämää ja pohdimme elämän eettisiä ja moraalisia periaatteita, kun katsomme elokuvia, televisiota, YouTubea, seuraamme blogeja tai kuuntelemme radiota. Usein tajuamme riippuvuutemme mediasta - hyvän elämän keskuksena - vasta, kun päivittäinen yhteydenpitomme syystä tai toisesta häiriintyy, verkkoyhteys katkeilee, kännykkä on kadonnut tai tietokoneen kovalevy on hajonnut. Arkemme häiriintyy, yhteydenpitomme maailman kanssa estyy (vrt. Turkle 2012).

Yhteiskunnan läpimedialisoituminen ei ole tietenkään tapahtunut hetkessä. Kyse on historiallisesta prosessista, johon liittyy kiinteästi tieteen ja teknologian kehitys, mutta myös laajemmat yhteiskunnalliset prosessit. Median merkitys yhteiskunnan keskeisenä instituutiona on voimistunut viimeisen sadan vuoden aikana. Krotz (2009, 21-40) korostaa, että medialisaatio liittyy yhteiskunnan muihin suuriin murroksiin, kuten modernisoitumiseen, yksilöllistymiseen, kaupungistumiseen ja teknologisoitumiseen. Palkkatyö, työn ja vapaa-ajan erottaminen toisistaan, muutto maalta kaupunkiin sekä perinteisten instituutioiden, kuten kirkon ja puolueiden, vallan heikkeneminen yhteiskunnan normien määrittelijänä ovat tehneet tilaa yhteiskunnalle, jossa median merkitys hyvän elämän esittäjänä ja rakentajana on entisestään vahvistunut. Kiteyttäen: välittäjästä on itsestään tullut keskus, kuten mediasosiologi Nick Couldry (2012, 2003) asian ilmaisee.

\section{JULKISUUDEN INTIMISOITUMINEN}

Hyvän elämän medialisoitu kommunikaatio on aina luonteeltaan jonkinasteisesti julkista. Kommunikaation julkisuuden asteet voivat toki vaihdella kahden ihmisen muodostamasta keskustelusta mediavälitteisessä julkisessa tilassa kuten Facebookissa (koskien vaikka moraalista arvostelua iltapäivälehden lööpistä) aina globaaliin julkisuuteen asti. Uusien mobiilien ja verkkopohjaisten kommunikaatiovälineiden myötä myös julkisuuden toimijoiden määrä on lisääntynyt. Esimerkiksi bloggauksen, statuspäivitysten, twiittien ja YouTube-videoiden myötä kysymys mediayhteiskunnan julkisuuden luonteesta on tullut yhä polttavammaksi (ks. esim. Meikle 2016). Tällä on ollut vaikutuksensa myös siihen, kuka pääsee julkisuudessa keskustelemaan hyvästä elämästä, millä tavalla näistä periaatteista keskustellaan, tai miten hyvää elämää mediassa esitetään.

Manuel Castellsia (2009) mukaillen voidaan ajatella, että kommunikaatiota hyvästä elämästä media- tai verkostoyhteiskunnassa, kuten Castells sitä nimittää, luonnehtii hyvin termi mass-self-communication eli henkilökohtainen joukkoviestintä. Kyse on joukkoviestinnästä siinä merkityksessä, että kommunikaation lähettäjällä on mahdollisuus tavoittaa jopa globaali yleisö esimerkiksi ladatessaan YouTube-videon verkkoon. Kyse on myös henkilökohtaisesta kommunikaatiosta, koska viestin lähettäjä on luonut, tuottanut ja lähettänyt viestinsä itse. Viestijä myös valitsee ympäristön, jonne hän viestinsä lähettää ja ohjaa siten kommunikaatioprosessia. (Castells 2009, 55.)

Mediayhteiskunnassa henkilökohtaisen joukkoviestinnän julkisuus on intimisoitunut monin tavoin (ks. esim. Berlant 2011; Illouz 2007; Furedi 2006). Antologiassa Tunteiden sosiologia I Sari Näre (1999b, 288) taustoittaa julkisuuden intimisoitumista osana yhteiskunnan moraalista murrosta seuraavaan tapaan: 
Tässä ilmiössä on kyse 1990-luvulla tapahtuneesta (media)julkisuuden intimisoitumisprosessista, joka vaikuttaa olevan yksityisen ja julkisen rajaa purkavan kiihtyvän modernisaation seurausta globaalin kapitalismin siivittämänä. [...] modernisaation myötä julkinen on alkanut läpäistä privaattia ja nyt myös privaatti julkista.

Edelleen Näre näkee median merkityksen keskeisenä tämän päivän mediayhteiskunnan tunteiden kanavoijana:

[...] Aikana, jolloin aatteisiin ja ideologioihin liittynyt tunnelataus on laimentunut, mediavälitteisten elämysten ja yksittäisten, kollektiivisten kokemusten voima saattaa kanavoida tunteita, joihin sisältyy koko yhteiskuntaa suuntaavia muutospotentiaaleja. Siinä missä 1970-luvulla kiillotettiin kollektiivisia viholliskuvia ja 1980-luvulla pelättiin ydinsotaa ja ydintuhoa, 1990-luvulla hyvinkin henkilökohtaisesti koetut ilon ja surun tunteet ovat saaneet hetkittäin jopa joukkoliikkeen voimaa [...] 1990-luvulla voimistunut julkisuuden intimisoituminen voi heijastaa läheisyyteen liittyvien tarpeiden problematisoimista. (Näre 1999a, 13-14.)

Näreen hahmottelema julkisuuden intimisoituminen on vahvistunut entisestään 2000-luvun jälkeisen julkisuuden digitalisoitumisen ja sosiaalisen median näkyvän kasvun myötä (ks. Papacharissi 2014). Tänä päivänä mediayhteiskunnassa hyvää elämää esittävät entistä useammin yksilöt, joilla on mahdollisuus saavuttaa yhä laajempia yleisöjä medialisoitumisen myötä (ks. esim. Couldry \& Hepp 2017). Tästä seuraa, että mediayhteiskunnan julkisuudessa tunteet ja intiimi nousevat hyvän elämän tuottamisen keskiöön.

TUNNUSTAMINEN HYVÄN ELÄMÄN TEKNOLOGIANA

Tunnustamisella hyvän elämän tuottamisen muotona on pitkä perinne länsimaisessa his- toriassa uskonnon, erityisesti kristinuskon, historiassa. Sitä kutsutaan ripittäytymiseksi (ks. esim. Ruokanen 1999). Kirjallisuudessa tunnustaminen on elänyt vuosisatoja yhtenä omaelämäkerrallisen kirjallisuuden lajityyppinä, kuuluisana esimerkkinä kirkkoisä $\mathrm{Au}-$ gustinuksen Tunnustukset (lat. Confessiones, kirjoitettu vuosina 397-398). Teoksessaan Seksuaalisuuden bistoria (osa II), Michel Foucault (1926-1984) tutkii tunnustamista yhtenä länsimaisen kulttuurin keskeisenä valtarakenteena. Olemme Foucault'n (1998) mielestä tunnustavia eläimiä. Länsimaisen tunnustajan historia kulkee kiteytetysti kirkon rippituolista lääkärin ja terapeutin vastaanotolle, televisiostudioon, sanomalehden lööppiin, verkon statuspäivityksiin tai videopäiväkirjaan (ks. Sumiala-Seppänen 2007; Talvitie-Lamberg 2014)

Olipa tunnustamisen paikka tai konteksti mikä tahansa, sillä on aina tietty kulttuurinen muotonsa, josta sen tunnistaa. Tunnustaminen edellyttää tunnustajaa, tahoa, joka tunnustusta vaatii, sekä armahtajaa tai tuomitsijaa (Sumiala-Seppänen 2007,171). Tämän päivän medialisoidussa tunnustamisessa tehtävänä on paljastaa totuus itsestään eli tehdä henkilökohtaisesta ja yksityisestä julkista julkisuudessa. Medialisoitua tunnustamista orkestroivat media-ammattilaiset: tuottajat, journalistit ja juontajat, jotka kutsuvat tunnustajia omiin virtuaalisiin rippituoleihinsa paljastamaan aidoimmat ja vilpittömimmät ajatuksensa ja tuntemuksensa tuhansille ellei miljoonille lukijoille ja katsojille (ks. Aslama \& Pantti 2007; White 1992; Peck 1995).

1990-luvulla suosituksi tulleiden talk show -ohjelmien keskeisenä ideana oli saada ruutuun ihmisiä kertomaan ja paljastamaan oman elämänsä yksityiskohtia. Tunnustus-puhetta sisältäviä ohjelmia voidaan tyypitellä niiden viihteellisyyden mukaan. Suomalaisessa televisiohistoriassa esimerkiksi Mirja Pyykön ja Maarit Tastulan vetämät keskusteluohjelmat tai Inbimillinen tekijä kuuluvat tunnustus-ohjelmien niin sanottuun vakavaan sarjaan. Oh- 
jelmissa käsitellään usein hyvin isoja ja vakavia teemoja, kuten kuolemaa, kärsimystä ja menetyksiä. Viihteellisempiä talk show -ohjelmia edustaa puolestaan 1990-luvun suomalaiseen televisiohistoriaan jälkensä jättänyt mediapersoona Jari Sarasvuonkin isännöimä Hyvät, pahat ja rumat (ks. Näränen 1996). Yhdysvaltalaisista esimerkeistä yksi tunnetuimpia on Oprah Winfrey-show (ks. Peck, 2009)

2000-luvun mediassa tunnustamista on harjoitettu etenkin erilaisissa tosi-tv-sarjoissa. Lajityypin esimerkkeinä mainittakoon Big Brother, Idols tai Huippumalli haussa (ks. van Zoonen \& Aslama 2006; Hill 2006). Tässä ohjelmaformaatissa yleisöä kutsutaan osallistumaan peleihin ja kilpailuihin, joiden tehtävänä on luodata osallistujien kykyjen lisäksi heidän persoonallisuuttaan ja yksityiselämäänsä. Tositv-sarjojen kirjo on laaja, mutta niille kaikille on tyypillistä leikki julkisen ja yksityisen, esittämisen ja paljastamisen välillä (ks. Deery 2015).

Lajityypin viehätys perustuu suurelta osin mahdollisuuteen tirkistellä ohjelmaan valittujen ihmisten elämää sekä vaikuttaa näiden kohtaloon kilpailussa äänestämällä. Myös katsojat saavat osallistua näihin medialisoituihin tunnustusrituaaleihin arvioimalla osallistujien tunnustuksia ja niiden aitoutta. Katsojatkin pääsevät osallistumaan tosi-tv:n nostattamiin moraalisiin keskusteluihin esimerkiksi osallistujien paheellisesta käytöksestä. Monissa ohjelmissa katsojat voivat myös vaikuttaa ohjelman kulkuun armahtamalla tai tuomitsemalla eli äänestämällä suosikkia tai pudottamalla pois muita kilpailijoita. (Sumiala-Seppänen 2007.) Tosi-tv-dramaturgiaan liittyvät kiinteästi kilpailijoiden tunnustukset, paljastukset omista tunteistaan ja ajatuksistaan sarjan edetessä tai esimerkiksi kilpailijoiden pudottua ohjelmasta. Keskeinen osa medialisoitua tunnustamista on tunnustusten kierrättäminen eri viestintävälineissä, kun myös muu media kommentoi kilpailijoita ja näiden kommentteja samalla kierrättäen niihin liittyviä moraalisia tuntemuksia.

Perinteisen, joukkoviestinten orkestroiman, medialisoidun tunnustustradition rin- nalle on etenkin parina viime vuosikymmenenä syntynyt myös aivan uudenlainen tunnustuskulttuuri, johon liittyy yksityishenkilöiden ja tavallisten ihmisten ennennäkemätön esiinmarssi julkisiksi tunnustajiksi, eräänlaisiksi julkisiksi hyvän elämän tavoittelijoiksi. 2000-luvun digitalisoitumisen myötä internet ja sosiaalinen media ovat synnyttäneet aivan uudenlaisen tunnustuskulttuurin mediaan. Tässä kulttuurissa jokaisesta voi tulla tunnustaja. Verkossa onkin lukuisia sivustoja, joilla median käyttäjä voi käydä tunnustamassa mitä erilaisimpia asioita omasta henkilökohtaisesta elämästään, liittyipä se sitten työhön, vapaaaikaan tai ihmissuhteisiin.

Lisäksi sosiaalinen media tarjoaa monia erilaisia foorumeja tunnustamiselle, joka voi liittyä esimerkiksi statuspäivityksiin tai YouTube-videoihin. Tunnustaminen on myös monien videobloggaajien keskeistä materiaalia. (Talvitie-Lamberg 2014). Lisäksi YouTube tarjoaa runsaasti tunnustuksellista arkistomateriaalia. Internetissä tapahtuvalle tunnustamiselle luonteenomaista on se, että siinä tunnustaja voi pysytellä jokseenkin nimettömänä ja tuntemattomana niin halutessaan. Sosiaalisen median tietyt yhteisöt muodostavat tästä poikkeuksen, sillä ne edellyttävät rekisteröitymistä yhteisön jäseneksi. Tunnustuksen aitoutta ei silti voi kummassakaan tapauksessa taata tai sen tarkistaminen voi olla ajoittain hyvin vaikeaa. Verkossa tunnustukset elävät myös syklisen kierron mukaan. Viime vuosina merkittäväksi levitys- ja kierrätyskanavaksi on noussut YouTube-nettivideosivusto. Sivustolta voi löytää tunnustuksia niin vanhoista talk show -ohjelmista, parhaillaan menevistä tv-ohjelmista kuin henkilökohtaisista videoistakin. Myös Facebook ja Twitter tarjoavat merkittävän alustan julkiselle tunnustamiselle. Nykymediassa tehdyille tunnustuksille on luonteenomaista, että on vaikea ennustaa, millaisen vastaanoton - hyväksyvän vai paheksuvan - näissä virtuaalisissa rippituoleissa tehdyt paljastukset saavat. Niitä kierrätetään eri välineissä, ne irtoavat alkuperäisistä yhteyksistään 
ja saavat uusia konteksteja. Tunnustuksia voi myös kommentoida periaatteessa kuka tahansa median käyttäjä lähettämällä omia viestejään. (Vrt. Sumiala 2008a.)

Yhteistä kaikille mediassa tapahtuville tunnustuksille on, että medialisoituna ilmiönä niissä asetetaan keskiöön itse tunnustustapahtuma, ei niinkään se, mitä tunnustetaan tai kuka tunnustuksen ottaa vastaan. Olipa tunnustaja sitten yksityishenkilö tai kuuluisuus, hän avaa oman yksityisen tilansa, vaikka sitten fiktiivisenkin, julkiseksi. Juuri itsensä paljastaminen avaa tunnustajan tien median rakentamaan ja ylläpitämään yhteiseen sosiaaliseen tilaan, hyvän elämän sfääriin. (Ks. myös Furedi 2006.) Merkityksellistä ei siten ole enää tunnustuksen sisältö, tai onko paljastus totta vai ei, vaan se, että tunnustus tehdään ja että se tehdään median hallitsemassa intiimin julkisuuden tilassa. Nick Couldrya (2012, 2003) mukaillen, kyse on median rituaalista, jonka avulla ja kautta tunnustajat liittyvät osaksi mediayhteiskunnan moraalista hyvän elämän keskusta - mediaa.

\section{TUNNUSTAMINEN JA HÄPEÄN PELKO}

Medialisoidun tunnustustapahtuman keskiössä hyvän elämän teknologiana on näin ollen yksityisen tekeminen julkiseksi. Katsoja, lukija tai kuuntelija kutsutaan tunnustustapahtumassa yksityisen alueelle jakamaan tunnustajan elämä. Prosessi on vahvasti tunnepitoinen sekä tunnustajan että vastaanottajan näkökulmasta. Tunnustajalle tunnustaminen tarjoaa mahdollisuuden nautintoon ja mielihyvään. Tunnustaminen tekee tunnustajan näkyväksi. Se kutsuu esille narsistista nautintoa nähdyksi tulemisesta ja katseen kohteena olemisesta. Tunnustaminen voi myös tuoda ilon, vapauden ja helpotuksen tunteen tunnustajalle. Taakka vähenee hartioilta, kun sen saa jakaa (vrt. Furedi 2006).

Katsojan näkökulmasta tunnustamiseen liittyvä mielihyvä voi kummuta voyerismis- ta, yksityiselämään tirkistelystä. Katsoja voi kokea myös helpotuksen tunteita tilanteessa, jossa hän samaistuu tunnustajaan. Tällöin hän tunnistaa tämän tunnustuksia myös omasta elämästään. Samaistuminen synnyttää myönteisiä yhteenkuuluvuuden tunteita tunnustajan ja tunnustuksen vastaanottajan välille (vrt. Mulvey 1973). Tunnustaminen palvelee tällöin eräänlaisena medialisoituna terapiana. Monet television talk show -ohjelmista, kuten Inbimillinen tekijä tai Dr. Phil, operoivat juuri positiivisen samaistamisen alueella. Yhdistävät emotionaaliset kokemukset syntyvät ohjelmassa jaetuista vaikeuksista (esimerkiksi alkoholismi, mielenterveyden ongelmat, hyväksikäyttö) ja niihin liittyvistä selviytymiskertomuksista. (Vrt. White 1992; Peck 1995.)

Kaikki tunnustamiseen liittyvät tunteet eivät suinkaan toimi sympaattisen ja/tai empaattisen samaistumisen alueella. Hänen paljastaessaan yksityiselämänsä asioita tunnustajaa uhkaa myös pelko joutua vastaanottajan hylkäämäksi tai torjumaksi. Tunnustajan paheellinen elämä torjutaan. Yleisö voi reagoida tunnustuksiin vihan, aggression ja tuomitsemisen lisäksi myös myötähäpeän tai jopa tietynlaisen voyeristisen sadismin sävyttämin tuntein. Tällöin tunnustamisen mielihyvään ja hyveellisen elämän tavoittelun projektiin kietoutuu halu nöyryyttää ja tulla nöyryytetyksi. (Vrt. Sumiala 2010, 2008b.)

Esimerkiksi Iso-Britannian 3. kauden (2002) Big Brother -kilpailijaan Jade Goodyyn kohdistettiin tällaisia hyvin ristiriitaisia tunteita ja haluja. Goodya paheksuttiin, ja samalla hän sai osakseen runsaasti julkisuutta ja hänestä tuli eräänlainen "tavis-julkkis" eli julkisuuden henkilö tavallisena ihmisenä. Osoituksena tästä Goody äänestettiin Britannian neloskanavan äänestyksessä vuonna 2003 Britannian neljänneksi huonoimmaksi ihmiseksi. Vuonna 2007 Goody osallistui Celebrity Big Brother -ohjelmaan, jota syytettiin rasismista intialaista näyttelijä Shilpa Shettyä kohtaan. Konflikti sai runsaasti huomiota niin Britannian, Intian kuin maailmankin 
viestimissä. Ohjelma menetti sponsoreitaan, ja Goody joutui lopulta nöyrtymään paheksunnan edessä ja pyytämään kommenttejaan julkisesti anteeksi. Vuonna 2008 Goody sairastui syöpään, johon hän kuoli vuotta myöhemmin, 22. maaliskuuta 2009. Tavis-julkkis Goody eli lyhyen aikaa, sairasti ja kuoli julkisuuden valokeilassa. Hänen merkityksestään mediayhteiskunnassa tapahtuvan moraalisen neuvottelun symbolina kertovat myös muistovideot, joita on löydettävissä esimerkiksi YouTubesta (vrt. Couldry 2009).

Esimerkkitapaus Goody vahvistaa käsitystä, että tunnustamisesta on tullut yksi mediayhteiskunnan hyvän elämän teknologioista. Sen ytimessä on hyveeksi nostettu itsensä paljastaminen kameran edessä tai bittiavaruudessa. Näin mediayhteiskunnan tunnustamisen psykodynamiikka syntyy ja elää jännitteestä, joka muodostuu tunnustajan (hyvän elämää tavoittelevan henkilön) ja yleisön (tunnustajaa moraalisesti arvioivan tahon) välille. Tällaiseen medialisoituun hyvän elämän tavoitteluun liittyvät olennaisesti myös häpeän ja vihan tunteet (ks. myös Scheff 1997).

Anthony Giddens $(1994,65)$ pitää häpeää keskeisenä myöhäismodernin yhteiskunnan psyykkisenä mekanismina ja moraalista käyttäytymistä ja toimintaa ohjaavana tekijänä. Häpeä on läheistä sukua syyllisyyden tunteelle, jonka Giddens esittää varhaisen modernin yhteiskunnan yhtenä ydintunteena. Giddensin mielestä häpeä liittyy aina ihmisen sisäistämään identiteettiin ja sen integriteettiin eli eheyteen, kun sen sijaan syyllisyys kumpuaa tunteista, jotka liittyvät siihen, että olemme tehneet väärin. Häpeä on ahdistusta ja angstia, joka syntyy, kun emme kykene ylläpitämään yhtenäistä ja/ tai moraalisesti ehjää kertomusta itsestämme. Häpeä on siten minää arvioiva tunne, ja siihen liittyy keskeisesti juuri paljastumisen kokemus. (Ks. myös Ronkainen 1999, 135.) Syyllisyydessä on kyse teosta tai tekemättä jättämisestä ja siihen liittyvästä tunteesta, jossa sisäinen minä kokee, että teko olisi tai ei olisi pitänyt tehdä; riittämättömyys on suhteessa tekoon. Syylli- syyttä tunteva minä paheksuu omaa toimintaansa. Häpeässä taas minä kääntää katseensa sisäänsä ja kohdistaa itseensä kelpaamattomuuden ja arvottomuuden tunteita. Kyse ei ole minän suhteesta tekoihin, vaan minän suhteesta omaan identiteettiin. Myös häpeä ja luottamus kietoutuvat toisiinsa. Kyky luottaa syntyy ihmisessä varhaislapsuudessa. Jos luottamus jostakin syystä vaurioituu tai jää kokonaan syntymättä, valtaa yksilön hylätyksi tulemisen pelko, jopa ontologinen turvattomuus. Näin ajattelee myös sosiaalipsykologi Thomas J. Scheff (1997), joka pitää häpeää yhtenä merkityksellisimpänä tunteena, joka liittyy sosiaalisten siteiden rakentamiseen ja ylläpitämiseen yhteiskunnassa.

VIHA JA HYVÄN ELÄMÄN EPÄVARMUUS

Entä miten häpeä tarkemmin katsoen kietoutuu hyvään elämään medialisoidussa tunnustamisessa? Suvi Ronkainen kirjoittaa häpeästä ja häpeämättömyydestä kulttuurissa seuraavaan tapaan:

Usein häpeää kuvataan tunteista kulttuurisimpana. Häpeä on sivilisoitunut ja sivilisoiva tunne. Sitä kuvataan ja joskus myös ylistetään keskeisenä moraalisena tunteena. Häpeämättömyys ei ole hyve vaan osoitus epäsosiaalisesta tai patologisesta narsismista. Häpeän kokeminen korvaa ulkoisen, näkyvän kontrollin ja on siksi keskeinen yhteiskunnallinen tunne. (Ronkainen 1999, 135.)

Edellä esitin, että nykyisessä mediayhteiskunnassa tapahtuvalle tunnustamiselle luonteenomaista on huomion kiinnittyminen itse tunnustamisen tapahtumaan, ei niinkään asioihin ja tekoihin, joita tunnustetaan. Tässä medialisoitu tunnustaminen eroaa merkittävästi esimerkiksi kristillisestä ripittäytymisestä. Syntinsä tunnustava saattoi luottaa siihen, että hänen tekonsa voitiin sijoittaa kirkon säätelemään moraalijärjestykseen oikean ja 
väärän, hyveiden ja paheiden akselille. Yhteisesti jaettu moraaliperusta tarjosi tunnustajalle mahdollisuuden myös vapautukseen, kirkon jakamaan armoon.

Myöhäis- tai jälkimodernissa mediayhteiskunnassa, jossa jaettu moraalinen perusta on hajonnut lukuisiksi moraalisiksi perustoiksi, jotka poikkeavat eri yksilöillä ja yhteisöillä toisistaan, hyvän elämän määrittely on käynyt entistä vaikeammaksi. Ristiriitaisten moraaliodotusten keskellä kamppailevan yksilön on yhä vaikeampi saada varmuutta siitä, milloin hänen toimintansa tuottaa hyvää elämää ja milloin ei. Baumanin (2006) ja Furedin (2006) termein tilanne synnyttää epävarmuutta, joka puolestaan saattaa näyttäytyä uhkana yksilön identiteetin eheydelle eli sisäiselle integriteetille, yksilöä koossapitäville jatkuvuuden tunteille. Tunnustaminen toimii tällaisessa tilanteessa hyvän elämän teknologiana, koska se tarjoaa mahdollisuuden sekä tunnustajalle että yleisölle julkiseen neuvotteluun hyvän elämän rajoista. Medialisoitu tunnustaminen näyttäytyy tienä häpeästä vapautumiseen - mahdollisuutena tulla nähdyksi ja hyväksytyksi toisten silmien edessä. Näin tunnustamisesta itsestään on muodostunut eräänlainen mediayhteiskunnan hyvän elämän teknologia.

\section{KIRJALLISUUS}

Aslama, Minna ja Pantti, Mervi 2007. ”Todellisuustelevisio, tunteet ja tunnustuspuhe.” Teoksessa Heikki Kujansivu ja Laura Saarenmaa (toim.): Tunnustus ja todistus. Näkökulmia kahteen elämän esittämisen tapaan. Helsinki: Gaudeamus.

Bauman, Zygmunt 2006. Liquid fear. Cambridge: Polity Press.

Berlant, Lauren 2011. Cruel Optimism. Durham: Duke University Press.

Castells, Manuell 2009. Communication power. Oxford: Oxford University Press.

Couldry, Nick 2012. Media, Society, World. Social Theory and Digital Media Practice. Cambridge, UK: Polity. Couldry, Nick 2003. Media rituals. A critical approach. Lon-
Kulttuurisen käytännön hälyvä moraalinen perusta kutsuu esille kuitenkin myös häpeää. Ulossulkemisen vaara ja paheksunta uhkaa jokaista, joka paljastaa yksityisyytensä toisten silmien edessä. Mediayhteiskunnan hyvän elämän teknologian, tunnustamisen, ytimessä on siten paradoksi. Emme koskaan voi olla varmoja, tuottaako mediayhteiskunnan meille tarjoama hyvän elämän teknologia lopulta moraalisesti ja eettisesti arvokasta elämää, vai sulkeeko se meidät ulkopuolelle yksinäisyyteen ja epävarmuuteen. Häpeään, joka voi synnyttää myös tuhoavaa vihaa itseä ja ympäristöä kohtaan.

Viime vuosien aikana mediassa on uutisoitu toistuvasti spektaakkelimaisista väkivallan teoista, Mark Juergesnmeyerin (2003) sanoin "terrorin teatterista", jota motivoi silmitön viha ja halu vahingoittaa itseä ja muita tavalla, joka herättää laajasti huomiota mediayhteiskunnassa. Tällainen viha ei synny mediayhteiskunnan ulkopuolella, vaan sen ytimessä. Nämä tuhoavat julkiset vihan tunnustukset eittämättä uhkaavat mediayhteiskuntaa - mutta samalla ne myös tekevät näkyväksi rujon logiikan, jonka varassa hyvää elämää mediayhteiskunnassa rakennetaan.

\section{— JOHANNA SUMIALA}

don: Routledge.

Couldry, Nick 2009. "From Durkheim on religion to Jade Goody on religious toleration."Teoksessa Christopher Deacy ja Elisabeth Arweck (toim.): Exploring religion and the sacred in a media age. Farnham: Ashgate Publishing.

Couldry, Nick \& Hepp, Andreas 2017. The Mediated Construction of Reality. Cambridge, UK: Polity.

Deuze, Mark 2013. Media Life. Cambridge, UK: Polity.

Foucault, Michel 1998. Seksuaalisuuden historia. Tiedontabto, nautintojen käyttö, huoli itsestä. Suom. Kaisa Sivenius. Helsinki: Gaudeamus. (Alkuperäiset tekstit vuosilta 1976 ja 1984.)

Furedi, Frank 2006. Therapy culture. Cultivating vulnerabi- 
lity in an uncertain age. London: Routledge.

Giddens, Anthony 1994. Modernity and self-identity. Self and society in the late modern age. Cambridge: Polity Press.

Hjarvard, Stig 2013. The Mediatization of Culture and Society. London: Routledge.

Illouz, Eva 2007. Cold Intimacies. The Making of Emotional Capitalism. Cambridge, UK: Polity.

Innis, Harold 1951. The Bias of Communication. Toronto: Toronto University Press.

Juergensmeyer, Mark 2003. Terror in the Name of God. The Global Rise of Religious Violence. Berkeley: California University Press.

Krotz, Friedrich 2009. "Mediatization: A concept with which to grasp media and societal change.”Teoksessa Knut Lundby (toim.): Mediatization. concepts, changes, consequences. New York: Peter Lang.

Lundby, Knut (toim.) 2014. Mediatization of Communication. Handbooks of Communication Science. Berlin: De Gruyter Mouton.

Mulvey, Laura 1973. "Visual pleasure and narrative cinema.” Teoksessa Jessica Evans ja Stuart Hall (toim.): Visual culture: The Reader. London and New York: Sage.

Meikle, Graham 2016. Social Media: Communication, Sharing and Visibility. New York: Routledge.

Näre, Sari 1999a."Tunteiden sosiologia yhteiskuntatutkimuksen kentässä.”Teoksessa Sari Näre (toim.): Tunteiden sosiologiaa I, Elämyksiä ja läheisyyttä. Helsinki: SKS.

Näre, Sari 1999b.”Sukupuolten tunnekulttuuri ja julkisuuden intimisoituminen.” Teoksessa Sari Näre (toim.): Tunteiden sosiologiaa I, Elämyksiä ja läheisyyttä. Helsinki: SKS.

Papacharissi, Zizi 2014. Affective Publics: Sentiment, Technology, and Politics: New York: Oxford University Press.

Peck, Janice 1995.”TVTalk shows as therapeutic discour- se: The Ideological labor of the televised talking cure." Communication Theory 5:1.

Ronkainen, Suvi 1999.”Subjektius, häpeä ja syyllisyys parisuhdeväkivallan elementteinä.” Teoksessa Sari Näre (toim.): Tunteiden sosiologiaa I, Elämyksiä ja läheisyyttä. Helsinki: SKS.

Ruokanen, Miikka 1999. ”Rippi armonvälineenä.” Teoksessa Pekka Kettunen (toim.): Käytännön ja teorian vuorovaikutus sielunhoidon teologiassa. Helsinki: Suomalainen Teologinen Kirjallisuusseura.

Scheff, Thomas J.1997. Emotions, the social bond, and human reality: part/whole analysis. Cambridge: Cambridge University Press.

Sumiala-Seppänen, Johanna 2007. "Tunnustan, olen siis olemassa - Myöhäismodernin mediakulttuurin terapeuttista eetosta etsimässä.” Teoksessa Heikki Kujansivu \& Laura Saarenmaa (toim.): Tunnustus ja todistus. Näkökulmia kahteen elämän esittämisen tapaan. Helsinki: Gaudeamus.

Sumiala, Johanna 2008a. "Circulation". Teoksessa David Morgan (toim.): Keywords in Religion, Media, and Culture. London: Routledge.

Sumiala, Johanna 2008b. "Georges Bataille and the Dark Side of the Social; The Case of Abu Ghraib.”Teoksessa Amanda Beech, Jaspar Joseph-Lester ja Matthew Poole. (toim.): Episode The Pleasure and Persuasion of Lens Based Media. London: Artwords Press.

Sumiala, Johanna 2010. Median rituaalit. Johdatus mediaantropologiaan. Tampere: Vastapaino.

Turkle, Sherry 2012. Alone Together: Why We Expect More from Technology and Less from Each Other. New York: Basic Books.

White, Mimi 1992. Tele-advising. Therapeutic discourse in American television. Chapel Hill: University of North Carolina Press. 